\title{
Original article (short paper) \\ Number of steps per day and the screening of cardiovascular disease risk factors in adolescents
}

\author{
Júlio Brugnara Mello \\ Universidade Federal do Rio Grande do Sul, Porto Alegre, RS, Brasil \\ Universidade Federal do Pampa, Uruguaiana, RS, Brasil \\ Vinícius Martins Farias \\ Mauren Lúcia de Araújo Bergmann \\ Gabriel Gustavo Bergmann \\ Universidade Federal do Pampa, Uruguaiana, RS, Brasil
}

\begin{abstract}
Pedometers have been used in some studies to measure physical activity in adolescents. However, cutoff points of steps per day that classify physical activity levels are not yet fully established. The aims of this study were to identify the possibility the number of steps/day to predict cardiovascular disease risk factors in adolescents and to propose cutoff points to the number of steps/day for adolescents. Method: 1,045 adolescents (51.7\% girls) aged 11-17 were randomly selected. The number of steps/day was measured using pedometers. The risk factors considered were total cholesterol, systolic and diastolic blood pressure, skinfold thickness and body mass index. The receiver operating characteristics (ROC) curve was used to analyze data. Results: ROC curve results indicated that the number of steps/day was able to predict increased systolic blood pressure in boys $(<16,134$ steps/day; $p=0.006)$, increased diastolic blood pressure in girls $(<12,399$ steps/day; $\mathrm{p}=0.023)$ and increased total cholesterol in both sexes $(<11,788$ steps/day for boys; $\mathrm{p}=0.016$ and $<9,400$ steps/day for girls; $\mathrm{p}=0.001)$. Conclusion: It is possible to identify adolescents that are more likely to have increased total cholesterol and blood pressure by the number of steps/day.
\end{abstract}

Keywords: pedometer, youngsters, cardiovascular health, ROC curve

\section{Introduction}

Cardiovascular diseases (CVD) are the leading cause of death worldwide and future estimation indicates that these diseases will continue to be the main cause of mortality in the coming decades (World Health Organization, 2008). The emergence of CVD seem to occur between the years of childhood and adolescence (Raitakari et al. 2003), and physical inactivity is considered a potential contributor to their genesis and development (Fogelholm 2010; Hallal et al. 2012). Furthermore, complying with physical activity guidelines at these periods of life contribute to health promotion not only immediately, but also throughout the lifetime (Trudeau, Laurencelle \& Shephard 2004).

Considering the health benefits resulting from physical activity during childhood and adolescence, a series of studies have been conducted in different laboratories (Bastos, Araújo \& Hallal 2008; Nelson, Neumark-Stzainer, Hannan, Sirard \& Story 2006; Oliver, Duncan, Kuch, McPhee \& Schofield 2012). In population studies, involving children and adolescents, questionnaires have been the most widely used instrument to measure physical activity. In this type of measurement, the most used classification and currently accepted measure is the sum of minutes in moderate to vigorous physical activity. Where individuals who accumulate 300 or more minutes per week of moderate to vigorous physical activity are classified as physically active (Haskell et al. 2007). However, some studies have used other instruments to estimate the level of physical activity in children and adolescents. Among them, pedometers have been an option adopted by some authors (Dollman, Olds, Esterman \& Kupke 2010; Le Masurier et al. 2005). This instrument has acceptable validity and reproducibility for the estimation of physical activity (Mckee, Boreham, Murphy \& Nevill 2005; Oliver, Schofield, Kolt \& Schluter 2007), bringing an alternative objective of measuring this variable in children and adolescents. Besides, compared with accelerometers, pedometers are less expensive and have a standardized unit of measurement (step/day). Considering these characteristics, pedometers offers a practical, low cost and easy universal interpretation way for an objective measurement of physical activity in free-living environments.

Although pedometer provides available objective information about the level of physical activity, there are still gaps in the classification of such information. Some proposals for the classification of physical activity using the number of steps/day for children and adolescents have as subjects of study children from 5 to 12 years old (Duncan, Al-Nakeeb, Woodfield \& Lyons 2007; Tudor-Locke et al. 2004), which compromises the use of these classifications in adolescents aged 13 and over. The proposal that covers the age group above 12 years of age (Dollman et al. 2010) is characterized, as well as the above proposals, by the use of only anthropometric indicators of overweight as a reference variable to the proposition of cutoffs points. These characteristics limit the use of these proposals of classification by the number of steps/day only for screening of overweight adolescents. 
Besides being overweight, the presence of other CVD risk factors have been reported and associated with the level of physical activity in adolescents (Martínez-Gómez et al. 2011). Thus, proposals of classifications for the number of steps/day considering different CVD risk factors should be performed providing information on its ability for screening each of these factors. In order to overcome these gaps, the aims of this study were a) to identify the number of steps/day capacity to predict CVD risk factors in adolescents and $b$ ) to propose cutoff points for the number of steps/day for adolescents.

\section{Methods}

\section{Sample selection}

The study sample was composed of students 11 to 17 years of age enrolled in private and public schools of Uruguaiana, Rio Grande do Sul, Brazil. The following criteria were adopted to calculate the sample size: a) estimated 15,913 school children in this age group according to 2011 census information on school population (public and private schools in the city); b) prevalence of $50 \%$ because of the study's characteristic of multiple outcomes; c) confidence interval of $95 \%(95 \% \mathrm{CI})$; d) sampling error of three percentage points; and e) increase of $15 \%$ to compensate possible losses and refusals. By the adoption of these criteria, it was estimated the need to assess 1,151 schoolchildren.

In order to respect the proportion of students from public and private schools and from the urban and rural areas in relation to the total number of schoolchildren of the city, the strategy for the selection of schools was carried out following two procedures. As the number of urban public school represented a majority $(86.8 \%)$ of the estimated total number of schoolchildren between 11-17 years old (from the sixth year of elementary school to the last year of high school) enrolled in the district. The selection process of the schools occurred in three stages while the selection of private schools and rural public schools occurred in two stages.

For the selection of urban public schools, the area of the city was proportionally divided into three geographic regions: northern, central and southern. The total number of public schools and students in each of the three regions was identified. The selection of students occurred by the draw of schools and classrooms that would participate in the study. All urban public schools in each of the three regions that had classes of the final years of elementary school and/or high school participated in the draw having the same chances to take part in the study according to the number of students aged 11-17 years. One school from each region was drawn. As the three selected schools had a high number of students in the age group of interest, even with the draw of classes. The number of students selected from each school was enough to represent the proportion of each region relatively to the total number of students enrolled at all urban public schools, without the need of drawing other urban public schools.

The selection process of private schools and rural public schools in the municipality was performed through a simple drawing. In order to have the number of schoolchildren selected proportional to the total number of students enrolled in the school system and in the area, it was necessary to draw just one rural school and one private school.

All students in the selected classes of the five schools drawn were invited to participate in the study. The adopted inclusion criterion for participation in the study was to be enrolled in the school system (public or private) of the municipality. The following criteria were used for exclusion: a) being outside the age group of interest; b) having any physical and/or cognitive limitations that could compromise the results; c) having stated that, during the days of using of the pedometer they did not perform routinely physical activities due to an injury or illness; and d) to be using any medication that could interfere the lipid profile or blood pressure. Such research had its project reviewed and approved by the ethics committee on human research.

\section{Data collection procedure}

The completion of the fieldwork occurred in four stages. First, after the draw of the five schools, contact was made with the representatives of the school boards for the presentation of the rationale, objectives and procedures of the study. All of the representatives of the school boards agreed with the study and the dates for data collections scheduled.

The second stage occurred with the visit to the selected classes for the study procedures presentation and to give the term of free and informed consent to each student. In the third stage occurred collections of data. The last phase of fieldwork consisted of another visit to the schools, in order to give an opportunity for the students, who forgot to deliver the consent form to their parents and for those who forgot to bring it back.

All measurements were performed on school premises in class time by an assessment team (teachers and scholarship/ physical education students) who had undergone training. The data collection occurred between April and October 2012.

\section{Variables}

The variables used for this study were gender, age, physical activity (PA) level and five CVD risk factors. The CVD risk factors considered were total cholesterol (TC), systolic blood pressure (SBP), diastolic blood pressure (DBP), skinfolds (SF) and body mass index (BMI). Gender and age were recorded on the same form in which the results of the other variables were noted.

The PA level was determined by the number of steps/day recorded by pedometers (Yamax Digi-Walker CW 700). Each individual used a pedometer for three consecutive days of a week. To implement this measurement, the students were initially instructed where to place it (waist) and how to wear the equipment (attached by an elastic belt given by the assessment team), the functioning of memory, and not to wear while conducting activities involving water (such as swimming and bathing) and while they slept. In the three days following the delivery of the pedometer to the school, members of the assessment team 
went to control the measurements of each unit, recording the number of steps within 24 hours of use, even when saved in the equipment's memory. The PA level was evaluated from the average number of steps of the second and third day, excluding values under 1,000 steps/day and over 30,000 steps/day mean values (Duncan, Schofield \& Duncan 2006).

The TC was obtained by using a portable monitor (Accutrend Plus, Roche Diagnostics). It was not required that the students were fasting since the TC shows no significant variation with the individual, in fasting state or not (BSC 2013). The use of this form of measurement of TC (portable monitor) and this procedure (not fasting) was used by the Brazilian Society of Cardiology involving more than 81 thousand individuals (Martinez et al. 2003). Values less than $150 \mathrm{mg} / \mathrm{dl}$ were considered "desirable", TC values between 150 and $170 \mathrm{mg} /$ dl were considered "borderline" and values equal or greater than $170 \mathrm{mg} / \mathrm{dl}$ were considered "increased", according to the IV Brazilian Guideline for Dyslipidemia and Atherosclerosis Prevention (Sposito et al. 2007). The inferential data analysis of both categories "borderline" and "increased" were grouped together and considered "increased".

The measures of SBP and DBP were conducted with individuals at sitting position for at least ten minutes. The measurement was performed by using a certified digital device (Christofaro et al. 2009) for checking blood pressure (Omron HEM 742). Three measurements were performed and the intermediate value was used. The classification of blood pressure was performed based on The Fourth Report on the Diagnosis, Evaluation, and Treatment of High Blood Pressure in Children and Adolescents (Falkner \& Daniels 2004), indicating "normal", "pre-hypertension" and "hypertension". For inferential data analyzes the "pre-hypertension" and "hypertension" categories were grouped and considered as "increased".

SF were collected using a scientific caliper (Cescorf, Brazil) and following the recommendations of Gordon et al. (1988). Measures of SF from subscapular and triceps regions were collected. The values of these SF were summed creating a variable sum of SF ( $\Sigma \mathrm{SF})$. The classification of $\Sigma$ SF values in "normal" and "increased" was held from the cutoff points proposed by the Physical Best (Going 1988).

BMI was estimated by dividing the body weight $(\mathrm{kg})$ by height $(\mathrm{m})$ squared $\left(\mathrm{kg} / \mathrm{m}^{2}\right)$. The measurement of body mass was performed with a digital scale with a capacity of $150 \mathrm{~kg}$ and a precision of 100 grams. To measure the height a portable stadiometer with a precision of $0.1 \mathrm{~cm}$ was used. The measurements were performed in a closed room following standardized procedures (Gordon et al. 1988). For the BMI classifications of "normal weight", "overweight" and "obesity" cutoff points proposed by Cole, Bellizzi, Flegal and Dietz (2000) were used. For inferential data analyzes the categories "overweight" and "obesity" were grouped and considered as "overweight".

\section{Data analysis}

Regarding the data processing, descriptive statistics were used at first. In these analyzes the mean values, standard deviation, minimum and maximum values of the number of steps/day were identified, as well as the values of absolute and relative frequency of other variables studied and their respective confidence interval of $95 \%(95 \% \mathrm{CI})$ was calculated. In order to compare the mean of number of steps/day between both genders the independent sample t-test was used and for the comparison of the mean number of steps/day between ages the one-way variance analysis (ANOVA) was used followed by Tukey's post-hoc test.

For the purpose of identifying the cutoff points from the number of steps/day the Receiver Operating Characteristic (ROC) curve was used. This procedure requires a dichotomous "reference" variable and a continuous "test" variable. In the present study, the reference variables were TC, SBP, DBP, $\Sigma$ SF, and BMI dichotomized. The test variable was the number of steps/day. For the identification of cutoff points initially the ROC curves' area values for each analysis and their respective $95 \%$ CI were analyzed. Only analyses with lower limit of $95 \%$ CI of the area under the ROC curve greater than $0.50(50 \%)$ were considered to identify the cutoffs points (Schisterman, Faraggi, Reiser \& Trevisan 2001). The next step was to identify the best balance between sensitivity and specificity, with these values being considered as cutoff for the number of steps/ day. All analyses were performed using the Software SPSS version 20.0 for Windows.

\section{Results}

A total of 1,300 adolescents were selected from the five participating schools. By refusing to participate, not having their parents' authorization, not attending on the day of data collection or failing to bring the consent form signed on the date set, 236 students did not participate in data collection, totaling 1,064 schoolchildren. Of these, 19 were not eligible according to inclusion criteria of the study. Of the total of 1,045 adolescents in the sample, 996 had steps/day recorded appropriately.

Table 01 presents the description results of the studied variables of the entire sample stratified by sex. The results indicated a high prevalence of overweight and obesity, increased adiposity and increased SBP.

Regarding the number of steps/day, in all ages there was a statistically significant difference between genders in favor of boys $(p<0.05)$. However, no differences were found between ages within the same gender, with the exception of 15 year old boys with a mean lower than 11 year old boys $(p<0.05)$ (Table 02).

As the number of steps/day showed no significant changes over the ages, the ROC curve analyses were performed stratified only by gender. Table 03 shows the results of the area under the ROC curve between the number of steps/day and the variable used as reference. Among all tested combinations, the results of the ROC curve analysis indicated that the number of steps/day was able to predict increased SBP in boys, increased DBP in girls and increased TC in both genders $(p<0.05)$. 
Table 1. Description of the studied variables in adolescents of 11 to 17 years old in Uruguaiana, Rio Grande do Sul State, Brazil, 2012.

\begin{tabular}{|c|c|c|c|c|c|c|}
\hline & \multicolumn{2}{|r|}{ Total } & \multicolumn{2}{|r|}{ Boys } & \multicolumn{2}{|r|}{ Girls } \\
\hline & n & $\%(95 \% C I)$ & n & $\%(95 \%$ CI $)$ & $\mathbf{n}$ & $\%(95 \% \mathrm{CI})$ \\
\hline Gender & - & - & 505 & $48.3(45.3-51.3)$ & 540 & $51.7(48.3-54.7)$ \\
\hline \multicolumn{7}{|l|}{ Age (Years) } \\
\hline 11 & 115 & $11.0(12.9-9.0)$ & 56 & $11.1(8.3-13.8)$ & 59 & $10.9(8.2-13.5)$ \\
\hline 12 & 184 & $17.6(15.1-20.0)$ & 109 & $21.6(18.0-25.1)$ & 75 & $13.9(10.9-16.8)$ \\
\hline 13 & 146 & $14.0(11.7-16.2)$ & 69 & $13.7(10.7-16.6)$ & 77 & $14.4(11.3-17.2)$ \\
\hline 14 & 124 & $11.9(9.8-13.9)$ & 58 & $11.5(8.7-14.2)$ & 66 & $12.2(9.4-14.9)$ \\
\hline 15 & 184 & $17.6(15.1-20.0)$ & 79 & $15.6(12.4-18.7)$ & 105 & $19.5(16.0-22.7)$ \\
\hline 16 & 145 & $13.9(11.6-16.1)$ & 60 & $11.9(9.0-14.7)$ & 85 & $15.7(12.6-18.7)$ \\
\hline 17 & 147 & $14.1(11.8-16.3)$ & 74 & $14.7(11.6-17.7)$ & 73 & $13.5(10.6-16.3)$ \\
\hline \multicolumn{7}{|l|}{ BMI } \\
\hline Normal weight & 732 & $70.9(68.1-73.6)$ & 339 & $68.5(64.4-72.5)$ & 393 & $73.0(69.2-76.7)$ \\
\hline Overweight & 218 & $21.1(18.6-23.5)$ & 112 & $22.6(18.9-26.2)$ & 106 & $19.7(16.3-23.0)$ \\
\hline Obesity & 83 & $8.0(6.3-9.6)$ & 44 & $8.9(6.3-11.4)$ & 39 & $7.2(5.01-9.3)$ \\
\hline \multicolumn{7}{|l|}{ Sum of Skinfold } \\
\hline Normal & 653 & $63.5(60.5-66.4)$ & 294 & $59.6(55.2-63.9)$ & 359 & $67.1(63.0-71.1)$ \\
\hline Increased & 375 & $36.5(33.5-39.4)$ & 199 & $40.4(36.0-44.7)$ & 176 & $32.9(28.8-36.9)$ \\
\hline \multicolumn{7}{|l|}{ TC } \\
\hline Desirable & 883 & 92.4 (90.7-94) & 427 & $95.3(93.3-97.2)$ & 456 & $89.8(87.1-92.4)$ \\
\hline Increased & 73 & $7.6(5.9-9.2)$ & 21 & $4.07(2.7-6.6)$ & 52 & $10.2(7.5-12.8)$ \\
\hline \multicolumn{7}{|l|}{ SBP } \\
\hline Normal & 792 & $79.8(77.3-82.2)$ & 377 & $79.2(75.5-82.8)$ & 415 & $80.4(76.9-83.8)$ \\
\hline Increased & 200 & $20.2(17.7-22.6)$ & 99 & $20.8(17.1-24.4)$ & 101 & $19.6(16.1-23.0)$ \\
\hline \multicolumn{7}{|l|}{ DBP } \\
\hline Normal & 920 & $92.2(90.5-93.8)$ & 445 & $93.3(91.0-95.5)$ & 475 & $92.1(89.7-94.4)$ \\
\hline Increased & 72 & $7.4(5.7-9.0)$ & 32 & $6.7(4.4-8.9)$ & 41 & $7.9(5.5-10.2)$ \\
\hline
\end{tabular}

Table 2. Description of the number of steps/day by gender and age in adolescents of 11 to 17 years old in Uruguaiana, Rio Grande do Sul, Brazil, 2012.

\begin{tabular}{cccccccccc}
\hline \multicolumn{9}{c}{ Boys } \\
\hline $\begin{array}{c}\text { Age } \\
\text { (Years) }\end{array}$ & Mean & SD & Min & Max & Mean & SD & Min & Max & p-value \\
\hline 11 & 14,381 & 5,944 & 1,147 & 27,586 & 11,678 & 5,505 & 2,206 & 24,582 \\
12 & 14,077 & 5,437 & 2,661 & 28,257 & 10,828 & 4,420 & 3,688 & 22,829 & 0,000 \\
13 & 13,307 & 5,327 & 3,812 & 29,591 & 11,442 & 4,655 & 1,415 & 24,292 & 0,000 \\
14 & 13,701 & 5,738 & 3,196 & 27,730 & 10,897 & 5,283 & 2,041 & 25,802 & 0,000 \\
15 & 12,341 & 5,642 & 3,139 & 27,313 & 11,231 & 5,438 & 2,579 & 28,407 & 0,000 \\
16 & 12,411 & 5,522 & 1,781 & 25,410 & 10,314 & 4,758 & 2,459 & 25,567 & 0,000 \\
17 & 12,585 & 5,719 & 1,689 & 25,935 & 10,592 & 4,303 & 2,517 & 23,584 & 0,000 \\
\hline
\end{tabular}

SD: Standard deviation; Min: Minimum value; Max: Maximum value.

Table 3. Area under the ROC curve between number of steps/day and cardiovascular disease risk factors in adolescents of 11 to 17 years old in Uruguaiana, Rio Grande do Sul, Brazil, 2012.

\begin{tabular}{ccccccccc}
\hline & \multicolumn{3}{c}{ Boys } & & \multicolumn{2}{c}{ Girls } \\
\hline & $\mathbf{n}$ & AURC & $\mathbf{9 5 \% C I}$ & $\mathbf{p}$-value & $\mathbf{n}$ & AURC & $\mathbf{9 5 \% C I}$ & p-value \\
\hline IMC & 495 & 0.55 & $0.49-0.60$ & 0.078 & 538 & 0.49 & $0.43-0.54$ \\
$\sum$ DC & 493 & 0.50 & $0.45-0.55$ & 0.872 & 535 & 0.50 & $0.45-0.55$ & 0.817 \\
CT & 395 & 0.66 & $0.54-0.79$ & 0.016 & 424 & 0.63 & $0.55-0.72$ & 0.001 \\
PAS & 476 & 0.59 & $0.53-0.65$ & 0.006 & 516 & 0.50 & $0.43-0.56$ \\
PAD & 476 & 0.52 & $0.42-0.62$ & 0.662 & 516 & 0.60 & $0.51-0.69$ & 0.921 \\
\hline
\end{tabular}

n: sample number (absolute frequency); AURC: area under ROC curve; 95\%CI: confidence interval of 95\%. 
Figure 1 presents the results of sensitivity and specificity found that showed the best cutoff point for the number of steps/day to screening adolescents with increased SBP (boys) and increased DBP (girls). The analysis indicated the cutoff point of 16,134 steps/ day for boys (Figure 1a) and 12,399 steps/day for girls (Figure 1b).
Figure 2 shows the results of sensitivity and specificity found that showed the best cutoff point for the number of steps/day to screening adolescents with increased TC. The analyses indicated cutoffs points of 11,788 steps/day for boys (figure $2 \mathrm{a}$ ) and 9,400 steps/day for girls (figure $2 \mathrm{~b}$ ).
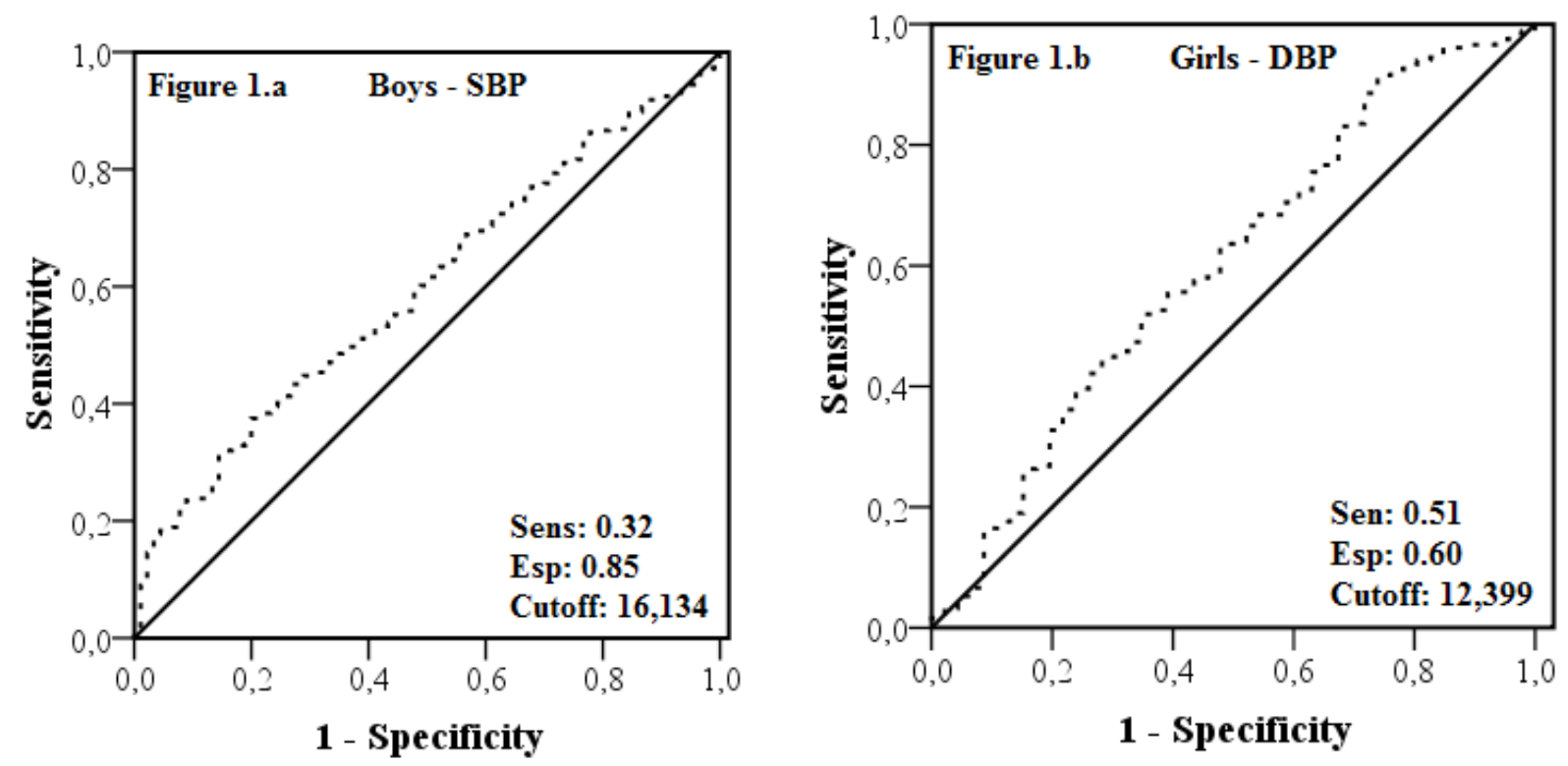

Figure 1. Area under ROC curve between the number of steps/day and the increased systolic blood pressure in boys (figure 1.a) and increased diastolic blood pressure in girls (figure 1.b).
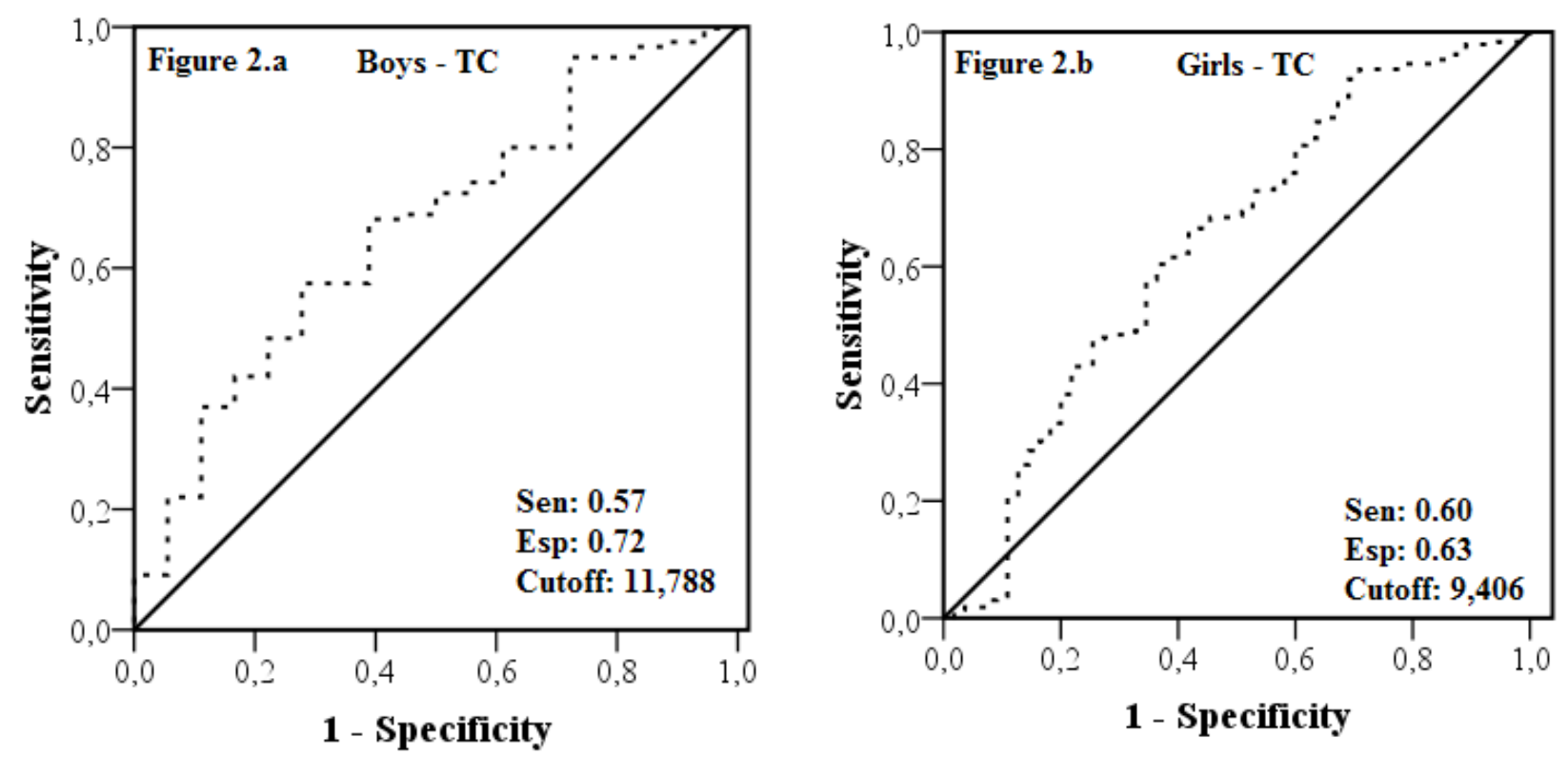

Figure 2. Area under ROC curve between the number of steps/day and increased total cholesterol in boys (figure 2.a) and girls (figure 2.b). 


\section{Discussion}

The results of this study indicated that the number of steps/ day can be used to screening adolescents that are more likely to exhibit increased BP and increased TC. Nevertheless, the required number of steps/day to reduce this probability varies depending on the risk factor used as reference and the proposed values that are different for girls and boys.

Regarding the mean number of steps/day, the values found in this study are similar to other developed with individuals from the same age group (Le Masurier et al. 2005). Studies with superior (Raustorp \& Ekroth 2010) and inferior (Beighle, Alderman, Morgan \& Masurier 2008; Hohepa, Schofield, Kolt, Scragg \& Garrett 2008) average number of steps/day to those found in the present study were also reported. The differences between the results of the studies, although not expressive, may be linked to different methodological approaches such as the number of days wearing the pedometer and the using of open or sealed pedometers. Moreover, socio-cultural characteristics of the regions where the studies were conducted may influence on how adolescents from different places walk.

Although small differences related to the average values of the number of steps/day have been found among the studies, the differences between genders were the same in all of them, where boys accumulated significantly more steps/day than girls. This gender difference can be attributed to higher number of steps during physical educations classes for boys than girls (Flohr, Todd \& Tudor-Locke 2006), and active transport more frequently found in boys than girls (Bastos, Araújo \& Hallal 2008). Furthermore, as suggested by Le Masurier et al. (2005), boys participate more in extracurricular physical activities. This hypothesis can help to explain this difference in number of steps/ day between genders. Another similarity between the analyzed studies refers to the average number of steps/day throughout different age groups, indicating no significant changes or only small decreases in the number of steps/day. The trend of decline in the number of steps/day can be associated to a reduction in participation in physical education classes (Le Masurier et al. 2005) and increase in sedentary behavior (Nelson et al. 2006) observed through the years of adolescence.

Regarding the cutoff points for the number of steps/day for adolescents some proposals are available in the literature (Andaki et al. 2013; Duncan et al. 2007; Tudor-Locke et al. 2004; Vincent \& Pangrazi 2012). However, except for the work by Andaki et al. (2013), the other studies used only anthropometric indicators of overweight to identify cutoff points for the number of steps/day. The present study was the only one to propose cutoff points from the association of the number of steps/ day with TC and BP in a representative sample of adolescents from 11 to 17 of both genders.

Unlike the studies of Tudor-Locke et al. (2004), Duncan et al. (2007), D ollman et al. (2010), Vincent \& Pangrazi (2012) and McCormack, Rutherford, Giles-Corti, Tudor-Locke and Bull (2011), in the present study the number of steps/day was not able to identify adolescents more likely to be overweight and to have increased SSF. However, Hands \& Parker (2008) also could not find association between the number of steps/ day and anthropometric indicators of being overweight in boys. Although physical activity contribute to body weight management, others factors have to be considered. Sedentary activities, food habits and biology factors as maturation and heredity can be linked to body weight increase. Thus, a combination of these factors should be considered in associations' analyzes between physical activity and anthropometric indicators of overweight in adolescents.

Although all the analyzed studies have aimed to propose cutoff points for the number of steps/day for children and adolescents, different values were found, ranging from 6,700 (Andaki et al. 2013) to 16,000 steps/day (Duncan et al. 2007; McCormack et al. 2011). These differences can be attributed to the different variables used as reference for the proposition of cutoffs, the way to dichotomize these variables, and the differences in the statistical approach. Thus, the recommendations for the number of steps/day for health promotion of adolescents should be interpreted considering the variable that was used as reference for its proposition. This form of interpretation and reflection about the recommendations and their possible practical applications are already being discussed in studies conducted with subjects from other age groups (Ewald, Attia \& McElduff 2014).

The present study has identified that 11,800 and 9,400 or more steps/day for boys and girls, respectively, are associated with reduced probability to present increased TC. For screening adolescents with increased BP, on the other hand, higher amounts of steps/day were identified. Around 16,000 and 12,400 steps/day for boys and girls, respectively.

The practical application of the found results could be made from the development of strategies for adolescents to increase their commuting by foot, stating that the number of steps per day is inversely associated to the presence of health outcomes. Furthermore, it is important to inform adolescents, parents and educators that the amounts of steps/day less than 11,800 (for boys) and 9,400 (for girls) are associated with higher likelihood of exposure to CVD risk factors. Although it is recommended that adolescents reach at least these amounts of steps/day, the main message should not be to fix the amount of steps/day to be achieved, but motivate them to increase their commutes by foot.

Further studies on the required number of steps/day for screening adolescents with increased likelihood of presenting or developing risk factors for CVD are required. These studies should be conducted with representative samples and covering all ages of adolescence. In addition, different variables should be used as reference for the proposition of cutoff points, enabling a greater understanding of the associations between the number of steps/day and different variables related to health.

Although this study has contributed to a better understanding about the classification of the level of physical activity of adolescents estimated by pedometers, some limitations should be discussed. Considering the pedometer as an instrument that only measures the amount of steps that the individual performs, without determining the intensity of the movements or discriminating the type of activity, it cannot predict the level of physical activity of an subject. However, when physical activity is analyzed in the health context, the number of steps/day can be 
a good parameter, since there is evidence indicating that walking, when practiced often, helps to prevent a number of chronic diseases such as type 2 diabetes, coronary heart disease, stroke and others (Andersen, Schnohr, Schroll \& Hein 2000). Despite the results presented between the CVD risk factors variables and the number of steps/day were significant, it is not possible to establish causality between them, since it is a cross-sectional study. Finally, the number of days that adolescents used the pedometer during the study was lower than other studies and they were not used during the weekends (Clemes \& Biddle 2013; Duncan et al. 2007; Tudor-Locke et al. 2004).

\section{Conclusion}

It is concluded that the number of steps/day can be used for screening adolescents with increased TC and increased BP. For adolescents from 11 to 17 years old, 11,800 and 9,400 steps/day were considered adequate to screening boys and girls, respectively, with likelihood of presenting or developing increased TC. For screening adolescents at age-matched group with increased likelihood of having or for developing increased BP, 16,000 and 12,400 steps/day for boys and girls, respectively, are considered adequate.

\section{References}

Andaki, A.C.R., Tinoco, A.L.A., Andaki Júnior, R., Santos, A., Brito, C.J., \& Mendes, E.L. (2013). Physical activity level as a predictor of cardiovascular risk factors in children. Motriz: Revista de Educação Física,19(3), 8-15.

Andersen, L.B., Schnohr, P., Schroll, M., \& Hein, H.O. (2000). Allcause mortality associated with physical activity during leisure time, work, sports, and cycling to work. Archives of internal medicine, 160(11), 1621-1628.

Bastos, J.P., Araujo, C.L., Hallal, P.C. (2008). Prevalence of insufficient physical activity and associated factors in Brazilian adolescents. Journal of physical activity \& health, 5(6),777-794.

Beighle, A., Alderman, B., Morgan, C.F., \& Masurier, G.L. (2008). Seasonality in children's pedometer-measured physical activity levels. Research quarterly for exercise and sport, 79(2), 256-260.

Clemes, S.A. \& Biddle, S.J. (2013). The use of pedometers for monitoring physical activity in children and adolescents: measurement considerations. Journal of physical activity and health, 10(2), 249-262.

Cole, T.J., Bellizzi, M.C., Flegal, K.M., \& Dietz, W.H. (2000). Establishing a standard definition for child overweight and obesity worldwide: international survey. Bmj, 320(7244), 1240.

Christofaro, D.G.D, Fernandes, R.A., Gerage, A.M., Alves, M.J., Polito, M.D. \& Oliveira, A.R.de. (2009). Validação do monitor de medida de pressão arterial Omron HEM 742 em adolescentes. Arquivos brasileiros de cardiologia, 92(1), 10-15.

Dollman, J., Olds, T.S., Esterman, A., \& Kupke, T. (2010). Pedometer step guidelines in relation to weight status among 5-to 16-year-old Australians. Pediatric exercise science, 22(2), 288.
Duncan, J.S., Schofield, G., \& Duncan, E.K. (2006). Pedometerdetermined physical activity and body composition in New Zealand children. Medicine and Science in Sports and Exercise, 38(8), 1402-1409.

Duncan, M.J., Al-Nakeeb, Y., Woodfield, L., \& Lyons, M. (2007). Pedometer determined physical activity levels in primary school children from central England. Preventive Medicine, 44(5), 416-420.

Ewald, B., Attia, J., \& McElduff, P. (2014). How many steps are enough? Dose-response curves for pedometer steps and multiple health markers in a community-based sample of older Australians. Journal of physical activity \& health, 11(3), 509-518.

Falkner, B., \& Daniels, S.R. (2004). Summary of the fourth report on the diagnosis, evaluation, and treatment of high blood pressure in children and adolescents. Hypertension, 44(4), 387-388.

Flohr, J.A., Todd, M.K., Tudor-Locke, C.E. (2006). Pedometer-assessed physical activity in young adolescents. Research quarterly for exercise and sport, 77(3), 309-315.

Fogelholm, M. (2010). Physical activity, fitness and fatness: relations to mortality, morbidity and disease risk factors. A systematic review. Obesity reviews, 11(3), 202-221.

Going, S. (1988). Physical Best - Body composition in the assessment of youth fitness. Journal of Physical Education, Recreation \& Dance, 59(7), 32-36.

Gordon, C.C., Chumlea, W.C., Roche, A.F., Lohman, T.G., Roche, A.F., \& Martorel, R. (1988). Anthropometric standardization: reference manual. Champaign. Anthropometric standardization: reference manual. Champaign.

Hallal, P.C., Andersen, L.B., Bull, F.C., Guthold, R., Haskell, W., Ekelund, U., \& Lancet Physical Activity Series Working Group. (2012). Global physical activity levels: surveillance progress, pitfalls, and prospects. The lancet, 380(9838), 247-257.

Hands, B.P., \& Parker, H. (2008). Pedometer-Determined physical activity, BMI and waist girth in 7-to 16-year-old children and adolescents. Journal of physical activity \& health, 5(Supp1), S153-S165.

Haskell, W.L., Lee, I.M., Pate, R.R., Powell, K.E., Blair, S.N., Franklin, B.A., ... \& Bauman, A. (2007). Physical activity and public health: updated recommendation for adults from the American College of Sports Medicine and the American Heart Association. Circulation, $116(9), 1081$.

Hohepa, M., Schofield, G., Kolt, G.S., Scragg, R., \& Garrett, N. (2008). Pedometer-determined physical activity levels of adolescents: differences by age, sex, time of week, and transportation mode to school. Journal of physical activity \& health, 5, S140.

Le Masurier, G.C., Beighle, A., Corbin, C.B., Darst, P.W., Morgan, C., Pangrazi, R.P., ... \& Vincent, S.D. (2005). Pedometer-determined physical activity levels of youth. Journal of physical activity \& health, 2(2), 159-168.

Martinez, T.L.R., Santos, R.D., Armaganijan, D., Torres, K.P., LouresVale, A., Magalhães, M.E., ... \& Ortiz, J. (2003). National alert campaign about increased cholesterol: determination of cholesterol levels in 81,262 Brazilians. Arquivos brasileiros de cardiologia, 80(6), 635-638.

Martínez-Gómez, D., Veiga, O.L., Gomez-Martinez, S., Zapatera, B., Calle, M.E., \& Marcos, A. (2011). Behavioural correlates of active commuting to school in Spanish adolescents: the AFINOS (physical activity as a preventive measure against overweight, 
obesity, infections, allergies, and cardiovascular disease risk factors in adolescents) study. Public health nutrition, 14(10), 1779-1786.

McCormack, G.R., Rutherford, J., Giles-Corti, B., Tudor-Locke, C., \& Bull, F. (2011). BMI-referenced cut-points for recommended daily pedometer-determined steps in Australian children and adolescents. Research quarterly for exercise and sport, 82(2), 162-167.

McKee, D.P., Boreham, C.A., Murphy, M.H., \& Nevill, A.M. (2005). Validation of the Digiwalker ${ }^{\mathrm{TM}}$ pedometer for measuring physical activity in young children. Pediatric Exercise Science, 17(4), 345.

Nelson, M.C., Neumark-Stzainer, D., Hannan, P.J., Sirard, J.R., \& Story, M. (2006). Longitudinal and secular trends in physical activity and sedentary behavior during adolescence. Pediatrics, 118(6), e1627-e1634.

Oliver, M., Duncan, S., Kuch, C., McPhee, J., \& Schofield, G. (2012). Prevalence of New Zealand children and adolescents achieving current physical activity and television watching recommendations. Journal of physical activity and health, 9(2), 173.

Oliver, M., Schofield, G.M., Kolt, G.S., \& Schluter, P.J. (2007). Pedometer accuracy in physical activity assessment of preschool children. Journal of Science and Medicine in Sport, 10(5), 303-310.

Raitakari, O.T., Juonala, M., Kähönen, M., Taittonen, L., Laitinen, T., Mäki-Torkko, N., ... \& Viikari, J.S. (2003). Cardiovascular risk factors in childhood and carotid artery intima-media thickness in adulthood: the Cardiovascular Risk in Young Finns Study. Jama, 290(17), 2277-2283.

Raustorp, A., \& Ekroth, Y. (2010). Eight-year secular trends of pedometer-determined physical activity in young Swedish adolescents. Journal of physical activity \& health, 7(3), 369.

Schisterman, E.F., Faraggi, D., Reiser, B., \& Trevisan, M. (2001). Statistical inference for the area under the receiver operating characteristic curve in the presence of random measurement error. American Journal of Epidemiology,154(2), 174-179.

Sposito, A.C., Caramelli, B., Fonseca, F.A., Bertolami, M.C., Afiune, N.A., Souza, A. D., ... \& dos Santos, F.R. (2007). IV Brazilian guideline for dyslipidemia and atherosclerosis prevention: Department of Atherosclerosis of Brazilian Society of Cardiology. Arquivos brasileiros de cardiologia, $88,2$.

Trudeau, F., Laurencelle, L., \& Shephard, R.J. (2004). Tracking of physical activity from childhood to adulthood. Medicine and Science in Sports and Exercise, 36(11), 1937-1943.

Tudor-Locke, C., Pangrazi, R.P., Corbin, C.B., Rutherford, W.J., Vincent, S.D., Raustorp, A., ... \& Cuddihy, T.F. (2004). BMIreferenced standards for recommended pedometer-determined steps/day in children. Preventive medicine, 38(6), 857-864.

Vincent, S.D., \& Pangrazi, R.P. (2002). An examination of the activity patterns of elementary school children. Pediatric Exercise Science, 14(4), 432-441.

World Health Organization (2008). The global burden of disease: 2004 update. WHO Library Cataloguing-in-Publication.

\section{Autor's note}

Júlio Brugnara Mello is affiliated with the University of Rio Grande do Sul. Research Group Sport Brazil Project (PROESP-Br) and University of Pampa. Research group in physical activity and health in childhood and adolescence.

Vinícius Martins Farias, Mauren Lúcia de Araújo Bergmann and Gabriel Gustavo Bergmann are affiliated with the University of Pampa. Research group in physical activity and health in childhood and adolescence.

\section{Acknowledgments}

This work was supported by a grant (public notice recently doctor - FAPERGS 001/2011) from Fundação de Amparo à Pesquisa do Estado do Rio Grande do Sul, Brazil (FAPERGS)

\section{Corresponding author}

Gabriel Gustavo Bergmann

University of Pampa. Research group in physical activity and health in childhood and adolescence. University of Pampa, Brazil.

BR 472, Km 592 - Post office box 118, Uruguaiana, RS, Brazil.

Email: gabrielgbergmann@gmail.com

Manuscript received on June 16, 2015

Manuscript accepted on February 02, 2016

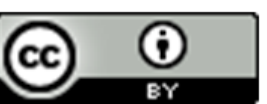

Motriz. The Journal of Physical Education. UNESP. Rio Claro, SP, Brazil - eISSN: 1980-6574 - under a license Creative Commons - Version 3.0 